\title{
Selected-control Synthesis of Metal Phosphonate Nanoparticles and Nanorods
}

\author{
Shu-Yan Song, Jian-Fang Ma, * Jin Yang, Min-Hua Cao and Ke-Chun Li \\ Department of Chemistry, Northeast Normal University, Changchun 130024, P. R. \\ China
}

E-mail:jfma@public.cc.jl.cn

\section{Supporting information:}

1. The experimental procedures are as follows: For sample 1 (nanoparticles), $0.4 \mathrm{mmol}$ $\mathrm{Co}\left(\mathrm{NO}_{3}\right)_{2} \cdot 6 \mathrm{H}_{2} \mathrm{O}, 0.4 \mathrm{mmol}$ sodium phenylphosphonate (SPP) were mixed with $10 \mathrm{ml}$ distilled water. The mixture was stirred for $40 \mathrm{~min}$ and then transferred into a teflon-lined autoclave maintained at $100{ }^{\circ} \mathrm{C}$ for $48 \mathrm{~h}$. The precipitate was collected and washed several times with distilled water. After drying in vacuum at room temperature, $\mathrm{Co}\left(\mathrm{O}_{3} \mathrm{PC}_{6} \mathrm{H}_{5}\right) \cdot \mathrm{H}_{2} \mathrm{O}$ nanoparticles were obtained. For sample 2 (nanorods), $0.4 \mathrm{mmol}$ SPP and $0.4 \mathrm{mmol}$ CTAB were mixed with $5 \mathrm{ml}$ water stirring for $40 \mathrm{~min}$ and then 0.4 mmol $\mathrm{Co}\left(\mathrm{NO}_{3}\right)_{2} \cdot 6 \mathrm{H}_{2} \mathrm{O}$ in $5 \mathrm{ml}$ water was added. After stirring for $10 \mathrm{~min}$, the mixture was transferred into a teflon-lined autoclave maintained at $100{ }^{\circ} \mathrm{C}$ for $48 \mathrm{~h}$. The precipitate was collected and washed several times with distilled water. After drying in vacuum at room temperature, $\mathrm{Co}\left(\mathrm{O}_{3} \mathrm{PC}_{6} \mathrm{H}_{5}\right) \cdot \mathrm{H}_{2} \mathrm{O}$ nanorods were obtained. For sample 3 (nanorods), $0.4 \mathrm{mmol} \mathrm{Co}\left(\mathrm{NO}_{3}\right)_{2} \cdot 6 \mathrm{H}_{2} \mathrm{O}$ and $0.4 \mathrm{mmol}$ SDBS were mixed with $5 \mathrm{ml}$ water stirring for $40 \mathrm{~min}$ and then $0.4 \mathrm{mmol} \mathrm{SPP}$ in $5 \mathrm{ml}$ water were added. After stirring for $10 \mathrm{~min}$, the mixture was transferred into a teflon-lined autoclave maintained at $100{ }^{\circ} \mathrm{C}$ for $48 \mathrm{~h}$. The precipitate was collected and washed several times with distilled water. After drying in vacuum at room temperature, $\mathrm{Co}\left(\mathrm{O}_{3} \mathrm{PC}_{6} \mathrm{H}_{5}\right) \cdot \mathrm{H}_{2} \mathrm{O}$ nanorods were obtained. $\mathrm{No} \mathrm{Co}\left(\mathrm{O}_{3} \mathrm{PC}_{6} \mathrm{H}_{5}\right) \cdot \mathrm{H}_{2} \mathrm{O}$ with other shapes were found in the syntheses of samples $\mathbf{2}$ and $\mathbf{3}$. All samples gave satisfactory microanalytical data.

2. Thermal gravimetric curve for sample 2 (Figure S1). The images of the samples obtained from different concentration ratio of [CTAB]:[SPP] (Figure S2 and S3). The 
TEM images of other transition metal phosphonates (Figure S4-S9). The simulated XRD powder pattern of $\mathrm{Co}\left(\mathrm{O}_{3} \mathrm{PC}_{6} \mathrm{H}_{5}\right) \cdot \mathrm{H}_{2} \mathrm{O}$ (Figure $\left.\mathrm{S} 10\right)$.

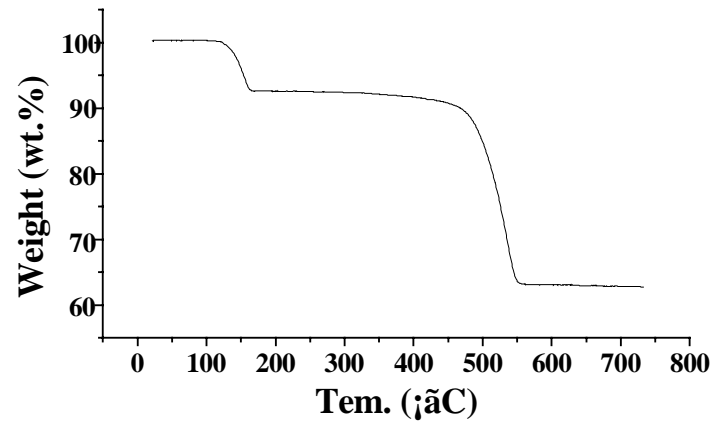

Figure S1. TG curve of sample 2.

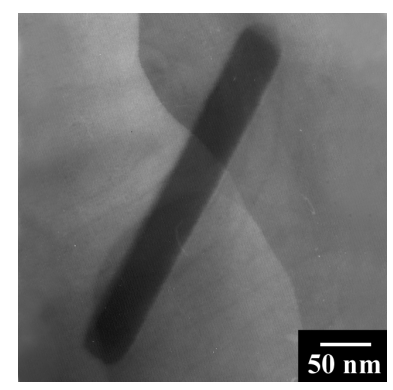

Figure S2. TEM image of the sample when $[\mathrm{SPP}]=5 \mathrm{mM},[\mathrm{CTAB}]=40 \mathrm{mM}$.

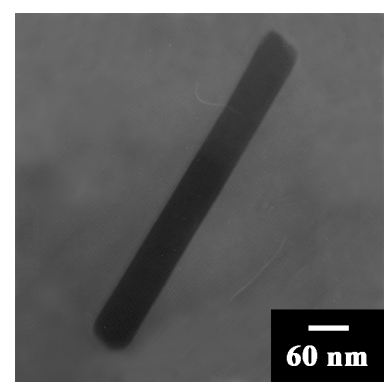

Figure S3. TEM image of the sample when $[\mathrm{SPP}]=20 \mathrm{mM},[\mathrm{CTAB}]=40 \mathrm{mM}$. 


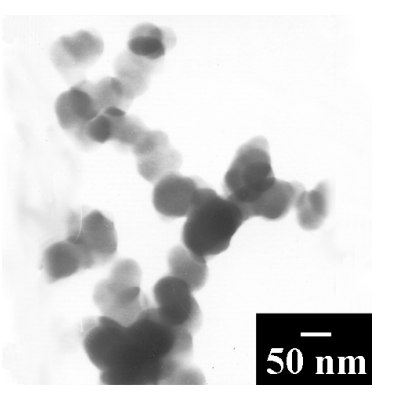

Figure S4. TEM image of the $\mathrm{Mn}\left(\mathrm{O}_{3} \mathrm{PC}_{6} \mathrm{H}_{5}\right) \cdot \mathrm{H}_{2} \mathrm{O}$ nanoparticles

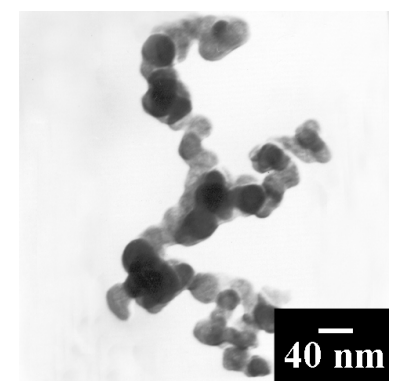

Figure S5. TEM image of the $\mathrm{Cu}\left(\mathrm{O}_{3} \mathrm{PC}_{6} \mathrm{H}_{5}\right) \cdot \mathrm{H}_{2} \mathrm{O}$ nanoparticles

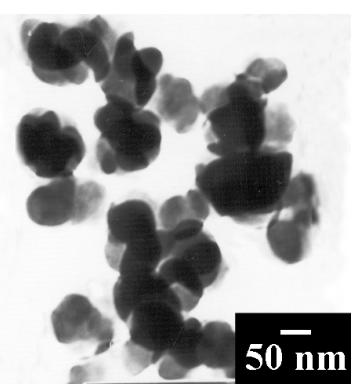

Figure S6. TEM image of the $\mathrm{Zn}\left(\mathrm{O}_{3} \mathrm{PC}_{6} \mathrm{H}_{5}\right) \cdot \mathrm{H}_{2} \mathrm{O}$ nanoparticles

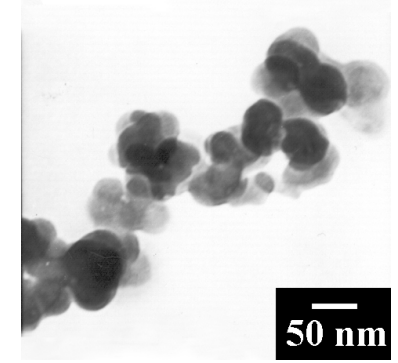

Figure S7. TEM image of the $\mathrm{Cd}\left(\mathrm{O}_{3} \mathrm{PC}_{6} \mathrm{H}_{5}\right) \cdot \mathrm{H}_{2} \mathrm{O}$ nanoparticles 


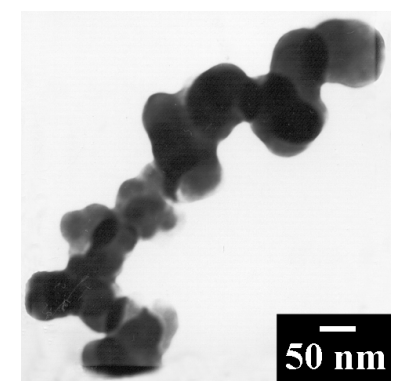

Figure S8. TEM image of the $\mathrm{Ni}\left(\mathrm{O}_{3} \mathrm{PC}_{6} \mathrm{H}_{5}\right) \cdot \mathrm{H}_{2} \mathrm{O}$ nanoparticles

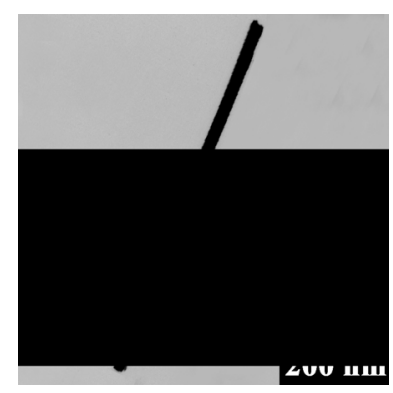

Figure S9. TEM image of the $\mathrm{Ni}\left(\mathrm{O}_{3} \mathrm{PC}_{6} \mathrm{H}_{5}\right) \cdot \mathrm{H}_{2} \mathrm{O}$ nanorod.

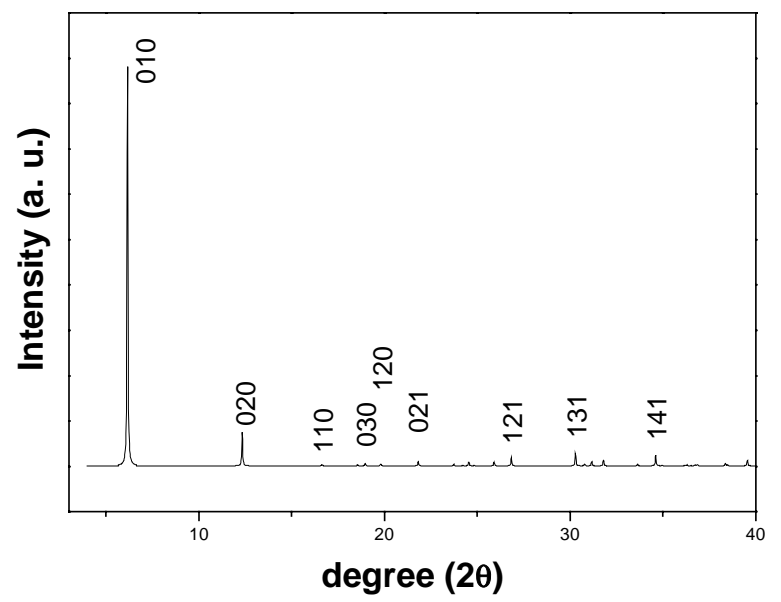

Figure S10. The simulated XRD powder pattern of $\mathrm{Co}\left(\mathrm{O}_{3} \mathrm{PC}_{6} \mathrm{H}_{5}\right) \cdot \mathrm{H}_{2} \mathrm{O}$ 